\title{
POR UM NATURAL DA NORMALIDADE: A PROBLEMATIZAÇÃO DO CONCEITO DE REALISMO NA ARTE ALEMÃ DO ENTRE-GUERRAS (1919-1938)
}

Vanessa Beatriz Bortulucce ${ }^{1}$

Como sabemos, a Alemanha foi derrotada na Primeira Guerra Mundial (1914-1918). Com a entrada dos Estados Unidos no conflito a partir de abril de 1917, o equilíbrio das forças beligerantes é afetado, favorecendo os exércitos aliados da Inglaterra e França. Assim, em 28 de setembro de 1918, os alemães foram definitivamente derrotados pelos exércitos aliados. Uma rebelião popular liderada pelos socialistas moderados ocorrida no país após o desfecho da guerra provocou a abdicação e a fuga do kaiser Guilherme II. Era o fim do Segundo Reich, que seria substituído pela República de Weimar, promulgada em 11 de agosto de 1919. Este novo governo assinou a rendição incondicional da Alemanha.

Com o final do conflito, as nações vencedoras, em um evento chamado Conferência de Paris determinaram, em junho de 1919, uma série de condições de paz impostas à Alemanha. O Tratado de Versalhes - este era o nome do documento que reunia estas cláusulas apresentou condições extremamente duras ao país perdedor: a Alemanha deveria reconhecer que fora a única e maior responsável pela deflagração da guerra; deveria pagar aos países aliados indenizações em dinheiro, minérios, produtos químicos e máquinas; perdeu todas as suas colônias, devolvendo a região de Alsácia-Lorena, rica em carvão, para a França; também foi proibida de manter um exército ativo, cancelando o alistamento militar e reduzindo drasticamente o número de soldados.

Os efeitos da Primeira Guerra Mundial obviamente não atingiram apenas a Alemanha. O evento enfraqueceu a Europa como num todo, principalmente em termos populacionais e econômicos. As nações combatentes estavam exaustas, muitas com a moral abalada. Após o armistício de 1918 a Europa, desiludida, não irá se animar o suficiente para acalentar metas utópicas e propostas revolucionárias - estas, defendidas principalmente pela arte não-figurativa produzida antes de 1914. O que passa a existir no cenário pós-guerra europeu é um esforço para agrupar as forças exauridas no sentido de recuperar e reconstruir uma ordem; trata-se, sobretudo, de buscar uma segurança e frear qualquer tipo de instabilidade que possa arruinar a sensação de caminhar sob terra firme novamente.

Esta necessidade de um retorno à ordem tornou-se uma espécie de slogan adotado pela Europa por toda a década de 20, embora tal empreitada fosse difícil de ser executada. O que de fato ocorreu ao longo daqueles dez anos foi a associação desta vontade de "pôr ordem na casa" aos governos totalitaristas que estavam ascendendo ao poder - Mussolini na Itália a partir de 1922, Stalin na Rússia em 1924 e Hitler na Alemanha em 1933. Nestes governos, o "restabelecimento da ordem", proclamado como vital por seus respectivos líderes apenas agravou algumas questões de ordem política e econômica, levando mais tarde à deflagração de outra guerra - a Segunda Guerra Mundial.

Neste período em que a Europa deseja urgentemente pôr-se de pé novamente, a arte testemunha, na Alemanha, o fortalecimento de uma pintura realista, que se torna um veículo para a manifestação dos problemas sociais e políticos que despontam como conseqüência da derrota alemã na guerra. A vanguarda continua ativa por toda a Europa, e não será diferente

1 Doutora em História da Arte - IFCH/UNICAMP. 
em solo germânico: é justamente na década de 20 que ocorrem experiências inovadoras no campo artístico. No caso da Alemanha, dois momentos merecem destaque dentro das tendências realistas e abstratas: a escola Bauhaus e a pintura da Nova Objetividade.

No mesmo ano em que nasce a República de Weimar, o arquiteto Walter Gropius inaugura a Bauhaus (em português, "Casa da Construção").

A Bauhaus foi uma escola de arquitetura e artes aplicadas fundada na cidade de Weimar sob a direção de Gropius; ela integrou a Academia de Belas Artes e a Escola de Artes e Ofícios da cidade alemã. Em 1925, a Bauhaus foi transferida para Dessau, instalando-se em edifícios concebidos por Gropius e seus colaboradores. Outro grande arquiteto, Ludwig Mies van der Rohe também chegou a dirigir a Bauhaus a partir de 1930, mas esta atividade teve pouca duração: quando os nazistas assumem o poder municipal em Dessau, a instituição é fechada. Tentativas posteriores de reabri-la foram dificultadas pela polícia, e, em 1933, a Bauhaus desaparece, sendo recriada anos depois em Chicago, com o nome de New Bauhaus.

Gropius concebeu a Bauhaus baseando-se nos preceitos de movimentos como o Arts and Crafts - criado na Inglaterra na segunda metade do século XIX: a revalorização do trabalho artesanal, junto com a colaboração da indústria. A estrutura teórica da Bauhaus constituía-se no conceito de uma Arte que englobasse todas as artes, tornando-se uma unidade, onde seriam eliminadas as distinções entre os elementos monumentais e aqueles decorativos. A Bauhaus não conhecia, portanto, aquela distinção de classe que mantinha separados o artesão e o artista. Arquitetura, pintura e escultura seriam uma só, dialogando constantemente entre si.

O corpo docente da Bauhaus contou com a presença de muitos artistas de destaque na época: Kandinsky, Paul Klee, Moholy-Nagy, entre outros. Uma das primeiras preocupações da Bauhaus foi o desenvolvimento da criatividade; para atingir este objetivo, era de fundamental importância estudar a transformação da forma plástica, analisar figuras geométricas, raciocinar sobre a cor, a linha, os materiais da arte. Kandinsky foi um dos artistas que pensou a respeito destas questões. Além de pintor e professor na Bauhaus, escreveu livros que tratavam de teorias artísticas da forma e da cor, como "Do espiritual na arte" e "Ponto e linha sobre um plano".

Muitas de suas obras possuem a intenção de apresentar um raciocínio livre, intuitivo (daí o conceito de 'espiritual'que Kandinsky apresenta em seus escritos) a respeito dos componentes básicos de uma pintura: pontos, linhas, cores, formas geométricas.

Mais tarde a escola assumiria um caráter mais funcional, elaborando um programa de trabalho que pudesse conduzir a resultados concretos. Assim, a Bauhaus desenvolve em seus laboratórios o desenho de peças industriais, mobiliário, utensílios domésticos de vários tipos, etc. Este design da Bauhaus foi marcado por uma severidade de formas e clareza de linhas, sem excessos.

O grande mérito da Bauhaus foi o de reunir o trabalho da vanguarda da arte moderna do período com as inovações tecnológicas, extraindo o melhor de cada uma para realizar uma síntese de ambas, ou seja, pensar os valores estéticos e funcionais de modo que estes possam residir, juntos, e de forma não conflituosa, nos objetos.

Enquanto a Bauhaus desenvolvia suas pesquisas vanguardistas sobre a plasticidade da forma, um outro tipo de arte estava sendo feita na Alemanha do período; uma arte que possuía uma ligação direta com os eventos decorrentes da derrota da Alemanha na Primeira Guerra 
Mundial, que propõe-se a apresentar a sociedade alemã deste pós-guerra, sem idealizações ou meio-termos.

Tal realismo desenvolvido na república de Weimar ficou conhecido como Nova Objetividade - Neue Sachlichkeit em alemão. Este termo surge inicialmente em 1923 como o título de uma exposição de pinturas de Max Beckmann, Otto Dix, e George Grosz. Assim, a Nova Objetividade apresenta-se como uma corrente marcadamente realista, que contrasta com as distorções de forma e cor do Expressionismo, bem como se opõe ao aspecto tipicamente emocional deste último. A "objetividade" reivindicada por estes artistas os leva a retratar uma sociedade doente, desumanizada, onde o pintor manifesta o seu próprio desengano com a vida. Neste sentido, a Nova Objetividade também contrasta com o Expressionismo, pois este último guiava-se por uma arte não engajada na problemática social.

As imagens das telas e desenhos característicos da Nova Objetividade são claras e detalhadas, muitas vezes de teor grotesco ou satírico. Nos desenhos e nas pinturas, a expressão de uma desilusão, um retrato das diferentes esferas sociais de uma Alemanha cansada, vencida pela guerra. A necessidade de retornar aos aspectos comuns da vida permeava toda a Europa no início dos anos 20, mas foi sentida sem dúvida mais intensamente na Alemanha.

Os dois artistas que merecem destaque dentro desta corrente são Otto Dix e George Grosz. Otto Dix foi implacável em reproduzir os horrores da guerra em telas e desenhos. Tornou-se conhecido através destas obras, que manifestavam um protesto pessoal contra as heranças de um conflito armado. Nada escapou ao pintor e artista gráfico: como uma espécie de repórter do front, ele mostra os mutilados pela guerra, a miséria, os cadáveres nas trincheiras, a burocracia e corrupção dos oficiais militares, a mediocridade dos endinheirados, que preferem dançar nos clubes e ignorar os que esmolavam nas ruas. Seus quadros muitas vezes são cínicos e incômodos, apresentando uma técnica realizada com esmero e detalhes quase fotográfico.

Em "Rua Prager", Dix apresenta ao espectador uma visão nada agradável das ruas da Alemanha do período. Os mutilados de guerra, os indigentes, os sem-teto, os mendigos, dividem a calçada com os trabalhadores anônimos, os magnatas e as mulheres perfumadas e bem-vestidas. A rua possui um nome específico, mas poderia ser muito bem, dentro da proposta de Dix, um modelo daquilo que se testemunhava em várias esquinas da Alemanha derrubada e abatida pela derrota na Primeira Guerra Mundial.

George Grosz é outro artista de destaque dentro da corrente da Nova Objetividade, que procura desmistificar as classes dirigentes da Alemanha. Desenhista e caricaturista, Grosz está particularmente interessado na questão do poder - quem o tem, e porquê, e como o usa. A partir daí, encontramos os burocratas, os capitalistas gananciosos, a burguesia cheia de afetações, o herói de guerra que passa fome, o militar com o peito cheio de insígnias que mergulha em luxúrias de todo tipo. $\mathrm{O}$ artista nos mostra que por trás do abuso de autoridade, da ganância pelo poder, da falta de escrúpulos, reside uma enorme neurose coletiva, um esfacelamento do mundo. Suas obras críticas continuariam mesmo depois de ele ter encontrado refúgio nos Estados Unidos, devido à sua perseguição pelos nazistas. Sua luta política continuou até ele não encontrar mais o estímulo para a revolta em território norteamericano.

Para Grosz e outros artistas, a República de Weimar foi ineficaz justamente por partilhar de posturas arraigadas do sistema judiciário, do clero e do corpo militar, os "pilares da 
comunidade" de acordo com Grosz, e título de uma de suas telas; também o fato de a Alemanha não ter tido nenhuma experiência democrática anterior agravou o cenário político, social e econômico do país. Esta república não entusiasmou a nação humilhada pela guerra, bem como os tais "pilares da comunidade" duramente representados por Grosz não possuíam um comprometimento sólido com a República; eles pareciam estar mais inclinados a aguardar o momento certo para adotar uma postura política extremista. Tais instituições não se esforçaram muito para contornar a crise surgida no país após a queda da bolsa em Nova York em 1929, que ocasionou desemprego (cerca de 6 milhões em 1932), inflação e miséria em massa na Alemanha e que terminou por fazer a República de Weimar ruir no início da década de 30 .

Em resumo, a corrente da Nova Objetividade foi caracterizada por uma renúncia ao mundo moderno e a sua estrutura burocrática; renunciou também a sociedade desumanizada pela máquina, e esta idéia sem dúvida é conseqüência dos eventos da Primeira Guerra, que mostrou ao mundo o potencial destrutivo da artilharia. Esta nova relação entre máquina e guerra marcou a Europa profundamente, e isto de uma certa forma refletiu-se na arte.

Assim, podemos observar a ocorrência, na Alemanha, de uma coexistência entre uma arte abstrata, estimulada pelas vanguardas européias, e a arte do Realismo, que pode ser considerada tão moderna quanto a abstrata, porém com uma temática e técnica distintas desta última. Contudo, ambas estão envolvidas, cada uma a seu modo, no debate sobre o que é considerado "arte realista". Observando as obras dos artistas da Nova Objetividade, dizemos que elas são mais objetivas e realistas do que as experiências realizadas na Bauhaus, por exemplo. Mas a arte abstrata possui ela mesma uma idéia do que seja a arte realista: é justamente aquela que está desatrelada dos efeitos ilusionistas típicos das academias e apresentadas nos salões oficiais; a arte realista, para eles, é aquela construída em bases geométricas e por processos mecânicos, sem nenhum estratagema que crie uma espécie de "faz de conta". Este inovador conceito de realidade na arte também foi defendido fervorosamente pelos artistas construtivistas russos logo após o processo revolucionário que tomou conta do país; contudo esta idéia foi condenada pelo regime político que se seguiu nos anos 20.

A coexistência pacífica de uma arte abstrata com uma outra figurativa não durou por muito tempo naqueles anos; os governos totalitários da Rússia e da Alemanha, apoiados em teorias confusas e preconceituosas, proibiram e perseguiram os artistas das vanguardas, repudiaram a Arte Moderna em geral, especialmente a abstrata, e forçaram os artistas nãoexilados a produzir uma arte condizente com o regime político. A arte dos regimes totalitários enfim abria espaço para manifestar-se numa Europa que sonhava com o "restabelecimento da ordem". 